\title{
É preciso viver mais e melhor
}

\author{
We need to live longer and better
}

$\mathrm{D}$ esde o final dos anos setenta, quando iniciaram mais amiúde as discussões sobre a saúde do homem¹, percebe-se real preocupação com a possibilidade de negligência do tema nos meios acadêmicos. Doença e morte são substantivos femininos e, por vezes, frágeis no ideário da cultura masculina para oferecer risco a sua integridade. No entanto, estudos evidenciam que homens são mais vulneráveis à doença e morrem mais precocemente do que mulheres ${ }^{2}$ e, a despeito disso, não procuram os serviços de atenção básica com a frequência desejável.

A concepção prevalente ainda é de masculinidade hegemônica e práticas de atenção à saúde são reconhecidas como comportamento de gênero. Mesmo quando se investiga sobre a saúde do homem, como ocorre através de dois artigos nesta edição de Ciência e Saúde, a preocupação do cuidado é, essencialmente, expressa pelas mulheres, pois estas representam sete dos nove autores envolvidos. Tanto o texto sobre o uso de medicamentos por homens, como aquele que trata de suas vivências frente ao diagnóstico de câncer de próstata mobilizam nossas melhores reflexões sobre este assunto e suas repercussões.

A Política Nacional de Atenção Integral à Saúde do Homem traz a possibilidade de qualificar a saúde da população masculina, com a perspectiva do desenvolvimento de linhas de cuidado que resguardem os princípios da equidade, integralidade e universalidade da atenção. Considerando que o SUS abarca um contingente de mais de 93 milhões de homens em território nacional, dos quais cerca de 52 milhões destes estão na faixa etária entre 20 e 59 anos $^{3}$, é fundamental o desenvolvimento de estratégias e ações que contribuam para seu acesso, acolhimento e a adesão aos serviços de atenção básica em saúde.

Ivan Carlos Ferreira Antonello Professor da Faculdade de Medicina da PUCRS

\section{REFERÊNCIAS}

1. Courtnay WH, Keeling RP. Men, gender, and health: toward na interdisciplinar approach. J Am College Health. 2000;48(6): 243-6. http://dx.doi.org/10.1080/07448480009596265

2. Schwarz E, Gomes R, Couto MT, Moura EC, Carvalho SA, Silva SFC. Política de Saúde do Homem. Rev Saúde Pública. 2012;46(Supl):108-116. http://dx.doi.org/10.1590/S0034-89102012005000061

3. Chakora ES. Política Nacional de Atenção Integral à Saúde do Homem. Esc Anna Nery 2014;18(4):559-561. http://dx.doi. org/10.5935/1414-8145.20140079 